$13^{\text {th }}$ International Conference on

AEROSPACE SCIENCES \& AVIATION TECHNOLOGY,

ASAT- 13, May 26 - 28, 2009, E-Mail: asat@mtc.edu.eg

Military Technical College, Kobry Elkobbah, Cairo, Egypt

Tel : +(202) $24025292-24036138$, Fax: +(202) 22621908

\title{
Numerical Modeling of Geometrical Analysis for Underground Structures
}

\author{
N. M. Nagy ${ }^{*}$, E. A. Eltehawy ${ }^{* *}$, H. M. Elhanafy ${ }^{* *}$ and A. Eldesouky ${ }^{* *}$
}

\begin{abstract}
The response of buried concrete structures to the effect of blast loads is of great importance. Various parameters including the depth and weight of explosive charge, soil properties and the relative location of the buried structure to the explosive charge affect the structural performance of buried structures. In this paper, the influence of burial depth of explosive charge is numerically investigated using the new proposed finite element model developed and described in a previous work for the authors. The burial depth of explosive charge is considered to be varied between $0.0 \mathrm{~m}$ to $6.0 \mathrm{~m}$. A comparison evaluation is carried out between the study of varying charge depth and the study of varying the burial depth of the structure. This investigation covers the blast wave propagation, structure response and damage analysis for buried reinforced concrete structures. The paper shows that buried explosions result in significant effects on the structure response than the surface explosions with the same conditions.
\end{abstract}

Keywords: buried structures - surface blast - finite element analysis - soil-blast interaction.

\section{Introduction}

In this paper, the response of a buried concrete structure to various factors affecting structural performance is investigated by carrying out a parametric study using the proposed new finite element model described in $[1,2]$. The parameters considered in this investigation are: depth of structural burial and charge depth of burial. These investigation covers the blast wave propagation, the structure response and damage analysis for buried reinforced concrete structures. This paper briefly discusses the overall analysis process to obtain an optimal design procedure for buried concrete structures subjected to blast loads. Because there have been no accurate established models governing the design of such a structure, a series of parametric studies has been carried out using the proposed numerical model in order to evaluate the significance and sensitivity of the depth of structural burial and charge depth of burial parameters on the structure response.

\section{2- Model description}

In this section, the proposed analysis procedure is used to undertake a two-dimensional (2D) axisymmetric analysis of the problem shown in Figure 1. The overall geometric model is divided into three different regions representing the soil, structure and explosive materials. The Arbitrary Lagrange Euler (ALE) formulation is used in the analysis to model both the charge region and the soil region close to the explosion. This is to eliminate the distortion of

\footnotetext{
*Egyptian Armed Forces, nabilmnagy@yahoo.com

Egyptian Armed Forces
} 
the mesh under high deformation [3,4]. On the other hand the conventional Finite Element Method (FEM) is utilised to model the rest of the system (the intermediate and far field soil mass and the structure itself). A convergence study involving mesh refinement, appropriate selection of element types and simulation of the infinite boundaries is initially performed; hence the optimum meshes are identified for the soil, explosive charge (TNT) and the structure, as shown in Figure 2. A TNT explosive charge is considered in this investigation with a mass of $M(\mathrm{Kg})$.

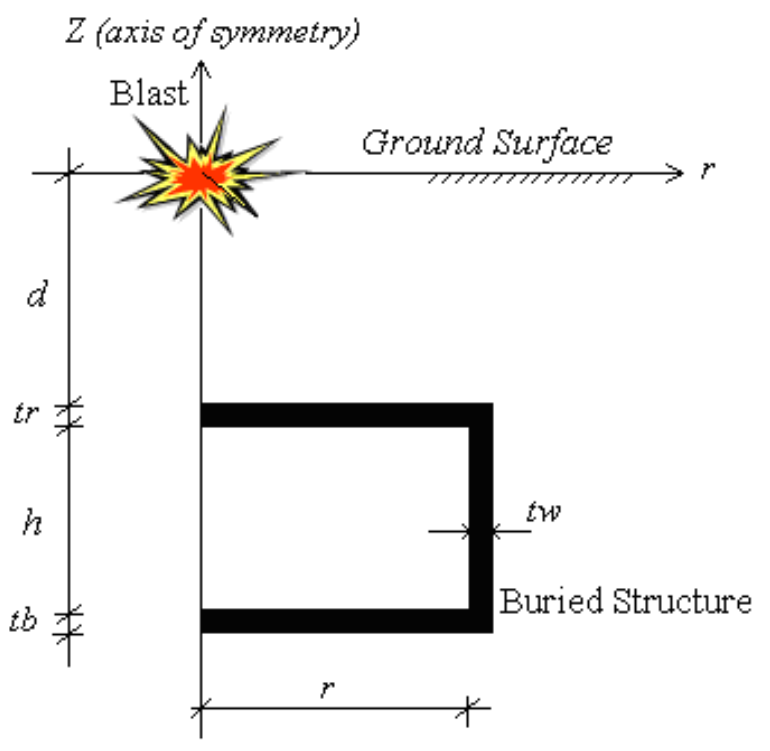

Figure 1 Schematic diagram of the example application

The structure is modeled as a cylindrical reinforced concrete structure with roof thickness of $t_{r}$ $(\mathrm{m})=0.5 \mathrm{~m}$, wall thickness of $t_{w}(\mathrm{~m})=0.5 \mathrm{~m}$ and floor plate thickness of $t_{b}(\mathrm{~m})=0.5 \mathrm{~m}$, internal height of $h(\mathrm{~m})=3.0 \mathrm{~m}$ and radius of $r(\mathrm{~m})=4.0 \mathrm{~m}$. The structure is buried in the soil at a depth of $d(\mathrm{~m})$ below the ground surface. The structure is centered under the explosive charge of $100 \mathrm{Kg}$ TNT as shown in Figure 1.

The burial depth of explosive charge is an important parameter for buried structure survival as the threat from explosive effects could be from underground explosions resulting from penetrating weapons at different depths. In this investigation the structure burial depth is chosen to be fixed throughout this study. It is taken with a constant depth of burial of $8.0 \mathrm{~m}$ in all cases which is found to be the most stable case (zero damage case) for the problem in hand in previous investigations [1]. The burial depth of explosive charge is considered to be varied between $0.0 \mathrm{~m}$ to $6.0 \mathrm{~m}$. A comparison evaluation is carried out between the study of varying charge depth and the study of varying the burial depth of the structure. The structural design of any underground structure considers static and dynamic loading effects. In this study, since the initial static stresses and pressures are all very small in comparison with the anticipated stresses generated by the explosion, the work presented concentrates on dynamic loading and results are presented in terms of dynamic response only. 


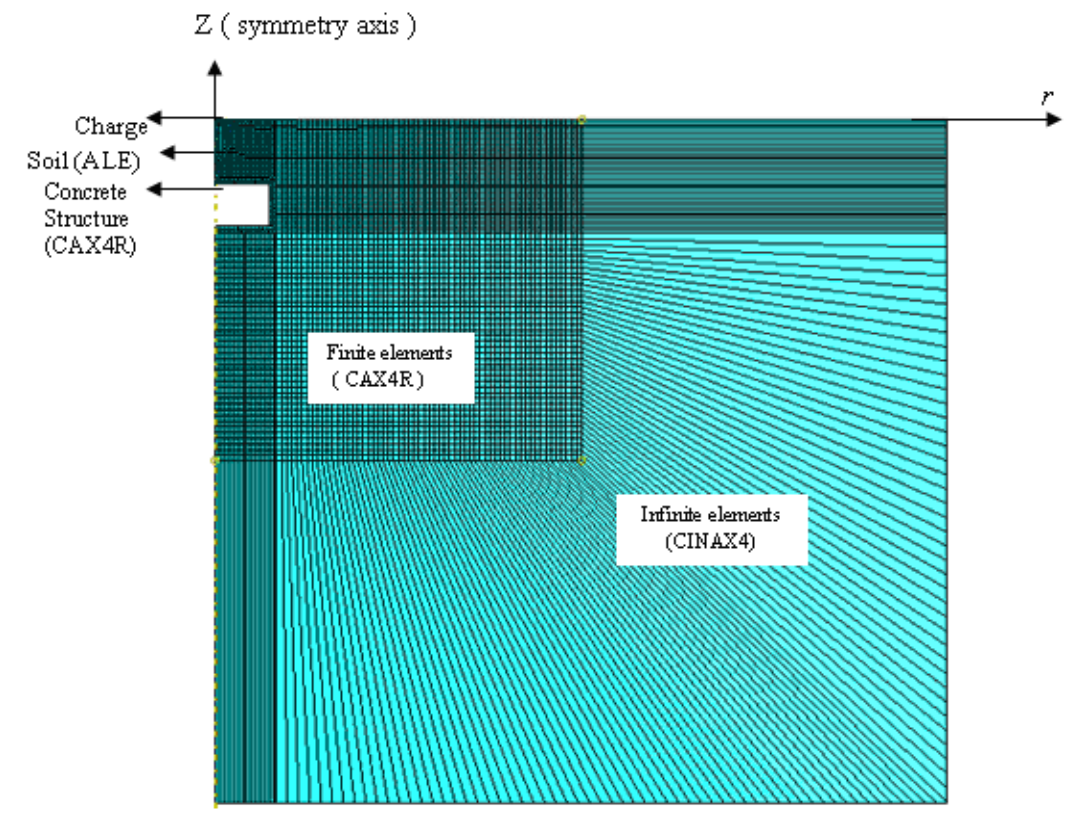

(a) View of overall entire problem

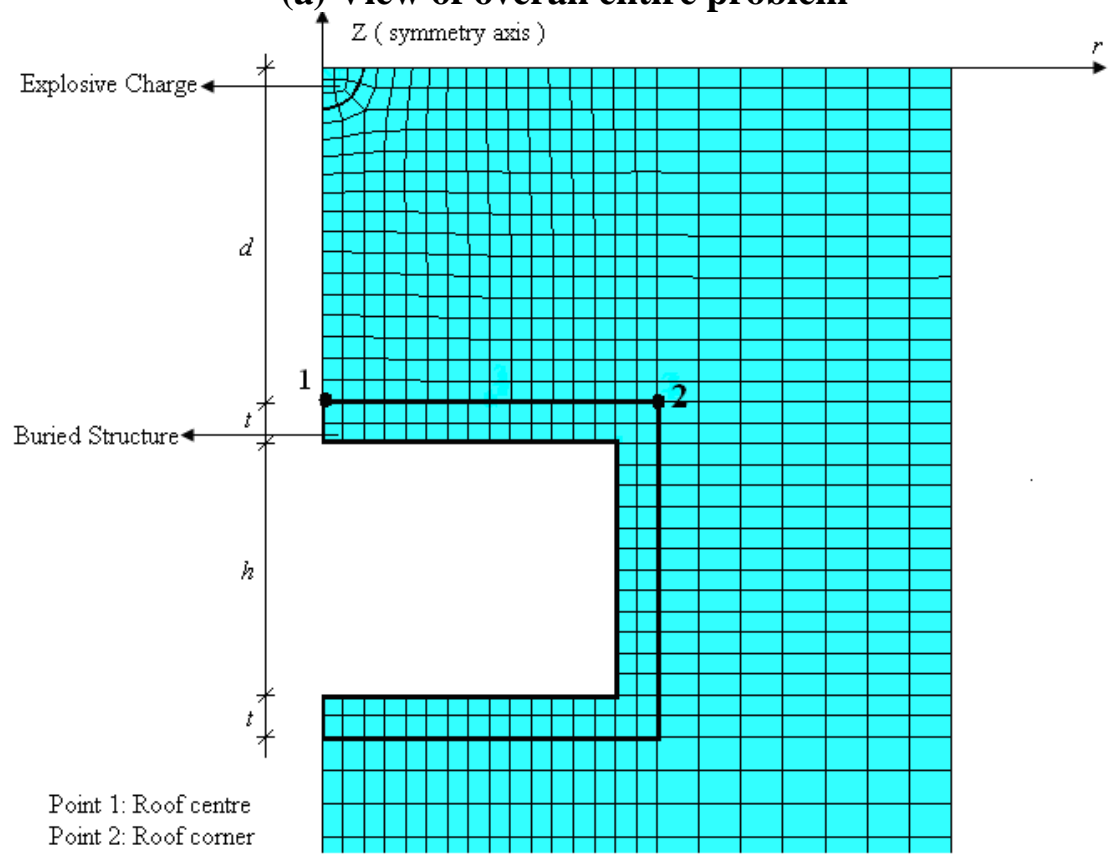

(b) Close up view of charge-structure and surrounding soil area

\section{Figure 2 Example problem - model discretisation}

The entire explosion-soil-structure system is represented by an assemblage of a finite number of 4-node bilinear axisymmetric quadrilateral, reduced integration elements (CAX4R) [5]. Smaller elements are used in the higher stress region and progressively larger elements in the lower stress region as shown in Figure 2. Symmetry boundary conditions are applied along the axis of symmetry by restraining the displacement in the radial direction. Infinite elements (CINAX4) [3] are used to provide quiet boundaries at the right side and bottom boundaries of 
the mesh as shown in Figure 2 a. The infinite elements help to minimize any spurious wave reflections [5] and thus simulate a boundary at infinity.

\section{3- The materials modeling}

The soil is considered as a very dry brown clay soil of classification CL [6] The soil behavior is modeled by an elasto-plastic Drucker-Prager Cap model as described in [5]. The model parameters used for the clay soil are shown in Table 1. The explosive charge (TNT) is modeled using the Jones-Wilkens-Lee (JWL) equation of state. It simulates the pressure generated by expansion of the detonation product [7]. The parameters for the TNT charge with the properties presented in [8] are listed here in Table 2. The mechanical behavior of the concrete structure is modeled using the Concrete Damage Plasticity (CDP) constitutive model [5]. The concrete parameters are obtained from [9] as shown in Table 3. The contact interface between the soil and the structure is simulated using the general Mohr-Coulomb friction concept, which allows for sliding, separation, and rebound between the buried structure surface and the surrounding soil. The dynamic behavior of the whole system is then evaluated using a numerical procedure.

Table 1 Material properties of the soil

\begin{tabular}{||l|c|}
\hline Parameters & Soil \\
\hline \hline Young's modulus $(E)$ & $51.7 \mathrm{MPa}$ \\
\hline \hline Poisson's ratio $(v)$ & 0.45 \\
\hline \hline Density $(\rho)$ & $1920 \mathrm{~kg} / \mathrm{m}^{3}$ \\
\hline \hline Material cohesion $(d)$ & $0.036 \mathrm{MPa}$ \\
\hline \hline Material angle of friction $(\beta)$ & $24^{\circ}$ \\
\hline Cap eccentricity parameter $(R)$ & 0.3 \\
\hline \hline Initial cap yield surface position $\left(\varepsilon_{\mathrm{v}}\right)$ & 0.02 \\
\hline \hline Transition surface radius parameter $(\alpha)$ & 0.05 \\
\hline \hline & $2.75 \mathrm{MPa}, 0.00$ \\
Cap hardening behaviour & $4.83 \mathrm{MPa}, 0.02$ \\
Stress, plastic volumetric strain $)$ & $5.15 \mathrm{MPa}, 0.04$ \\
& $6.20 \mathrm{MPa}, 0.08$ \\
\hline
\end{tabular}

Table 2 JWL parameters used for modeling TNT explosive

\begin{tabular}{|l|c|}
\hline Parameter & value \\
\hline \hline Detonation Wave Speed, $C_{d}$ & $6930 \mathrm{~m} / \mathrm{s}$ \\
\hline $\mathrm{A}$ & $373.8 \mathrm{GPa}$ \\
\hline $\mathrm{B}$ & $3.747 \mathrm{GPa}$ \\
\hline $\mathrm{R}_{1}$ & 4.15 \\
\hline $\mathrm{R}_{2}$ & 0.9 \\
\hline$\omega$ & 0.35 \\
\hline The Density of The Explosive $\rho_{0}$ & $1630 \mathrm{Kg} / \mathrm{m}^{3}$ \\
\hline Initial Specific Energy $E_{m 0}$ & $3.63 \mathrm{Joule} / \mathrm{kg}$ \\
\hline
\end{tabular}


Table 3 Material properties of the RC structure [9]

\begin{tabular}{|c|c|c|c|}
\hline \multicolumn{2}{|c|}{ The parameters of CDP model } & \multicolumn{2}{|c|}{ Value } \\
\hline \multicolumn{2}{|c|}{ Young's modulus E (GPa) } & \multicolumn{2}{|c|}{19.7} \\
\hline \multicolumn{2}{|c|}{ Poisson's ratio $v$} & \multicolumn{2}{|c|}{0.19} \\
\hline \multicolumn{2}{|c|}{$\beta$} & \multicolumn{2}{|c|}{$38^{0}$} \\
\hline \multicolumn{2}{|c|}{ Flow potential eccentricity $(\varepsilon)$} & \multicolumn{2}{|c|}{1} \\
\hline \multicolumn{2}{|l|}{$\sigma_{b 0} / \sigma_{c 0}$} & \multicolumn{2}{|c|}{1.12} \\
\hline \multicolumn{2}{|l|}{$\mathrm{K}_{\mathrm{c}}$} & \multicolumn{2}{|c|}{0.666} \\
\hline \multicolumn{2}{|c|}{ Concrete compression hardening } & \multicolumn{2}{|c|}{ Concrete compression damage } \\
\hline Stress $[\mathrm{Pa}]$ & Crushing strain & Damage & Crushing strain \\
\hline $15.0 \mathrm{e} 6$ & 0.0 & 0.0 & 0.0 \\
\hline $20.197804 \mathrm{e} 6$ & 0.0000747307 & 0.0 & 0.0000747307 \\
\hline $30.000609 \mathrm{e} 6$ & 0.0000988479 & 0.0 & 0.0000988479 \\
\hline $40.303781 \mathrm{e} 6$ & 0.000154123 & 0.0 & 0.000154123 \\
\hline $50.007692 \mathrm{e} 6$ & 0.000761538 & 0.0 & 0.000761538 \\
\hline $40.236090 \mathrm{e} 6$ & 0.002557559 & 0.195402 & 0.002557559 \\
\hline $20.236090 \mathrm{e} 6$ & 0.005675431 & 0.596382 & 0.005675431 \\
\hline $5.257557 \mathrm{e} 6$ & 0.011733119 & 0.894865 & 0.011733119 \\
\hline \multicolumn{2}{|c|}{ Concrete tension stiffening } & \multicolumn{2}{|c|}{ Concrete tension damage } \\
\hline Stress $[\mathrm{Pa}]$ & Cracking strain & Damage & Cracking strain \\
\hline $1.99893 \mathrm{e} 6$ & 0.0 & 0.0 & 0.0 \\
\hline $2.842 \mathrm{e} 6$ & 0.00003333 & 0.0 & 0.00003333 \\
\hline $1.86981 \mathrm{e} 6$ & 0.000160427 & 0.406411 & 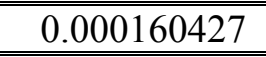 \\
\hline $0.862723 \mathrm{e} 6$ & 0.000279763 & 0.69638 & 0.000279763 \\
\hline $0.226254 \mathrm{e} 6$ & 0.000684593 & 0.920389 & 0.000684593 \\
\hline $0.056576 \mathrm{e} 6$ & 0.00108673 & 0.980093 & 0.00108673 \\
\hline
\end{tabular}

In changing depth investigations it is assumed that the soil properties are still the same with varying the depth while in practice it will be changing with the increasing the depth as the soil strength is increasing. This trend will be exacerbated by the fact that as burial depth increases there will be an increasing tendency to construct the structure in heading rather than using the cut-and-cover method which undoubtedly would be preferred at shallow burial depths. In this study, since the initial static stresses and pressures are all very small in comparison with the anticipated stresses generated by the explosion, the work presented concentrates on dynamic loading and results are presented in terms of dynamic response only.

In all of these investigations, the analysis includes consideration of the contact soil pressure, the roof slab response, evaluation of the overall structure damage and the stress distribution throughout the concrete structure. In addition trend relations are conducted between the structure response and the effect of the investigated parameters.

\section{4- The depth of explosive charge burial variation effect investigation}

In order to study the effect of varying the explosion depth on the structural response, the finite element analysis has been conducted using the same model and material parameters and with explosion depths of burial of $0.0 \mathrm{~m}$ (surface charge), $2.0 \mathrm{~m}, 4.0 \mathrm{~m}$ and $6.0 \mathrm{~m}$ with a constant 
structure depth of burial of $8.0 \mathrm{~m}$ in all cases which is found to be the most stable case (zero damage case) in previous investigations [1]. This range is chosen in order to compare the results of this study with the results from the study of the structural depth of burial effects and investigate the effect of soil cover thickness on the structure response as shown in Figure 3

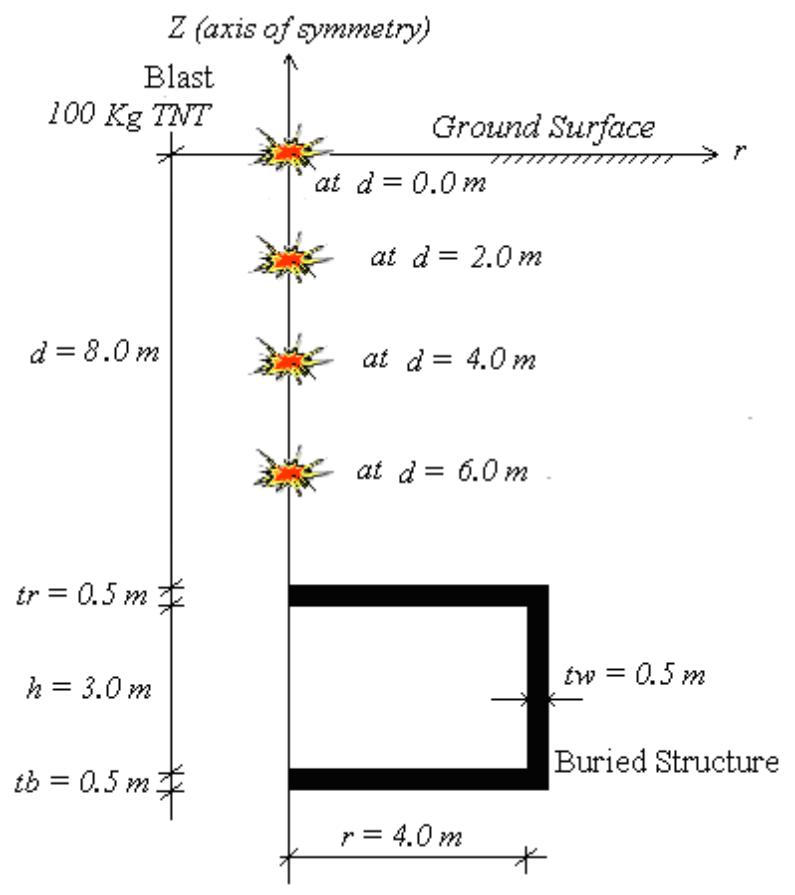

Figure 3 Schematic diagram of charge depth study case

\section{5- Results and analysis}

\subsection{The structure roof response}

Figure 4 presents the variation of vertical displacement time histories on the roof slab centre with changes in charge burial depth. It can be seen that a noticeable increase in the structure response occurs with the charge depth of burial increase. It can also be seen that significant permanent vertical displacements of the roof structure slab occur in cases of charge depths of burial range from $4.0 \mathrm{~m}$ depth to $6.0 \mathrm{~m}$ depth (with order of $7.0 \mathrm{~mm}$ to $32.0 \mathrm{~mm}$ ). These residual deflections indicate the occurrence of plastic deformation of the roof slab under the effect of blast loads. For charge burial depths in range from surface explosion $(0.0 \mathrm{~m}$ depth) to $2.0 \mathrm{~m}$ depth, no permanent displacements are experienced.

\subsection{The structure damage}

Figure 5 shows the concrete tensile damage in the structure as charge depth of burial varies. The maximum tensile damage value reaches 0.98 at the roof centre at a charge depth of $6.0 \mathrm{~m}$. This is due to the direct impact shock of the blast wave on the roof centre. This maximum value of damage decreases with reducing the depth of charge burial until reaching zero damage in the case of a surface charge. Provided the soil cover is $\geq 6.0 \mathrm{~m}$ a satisfactory level of protection is obtained. 


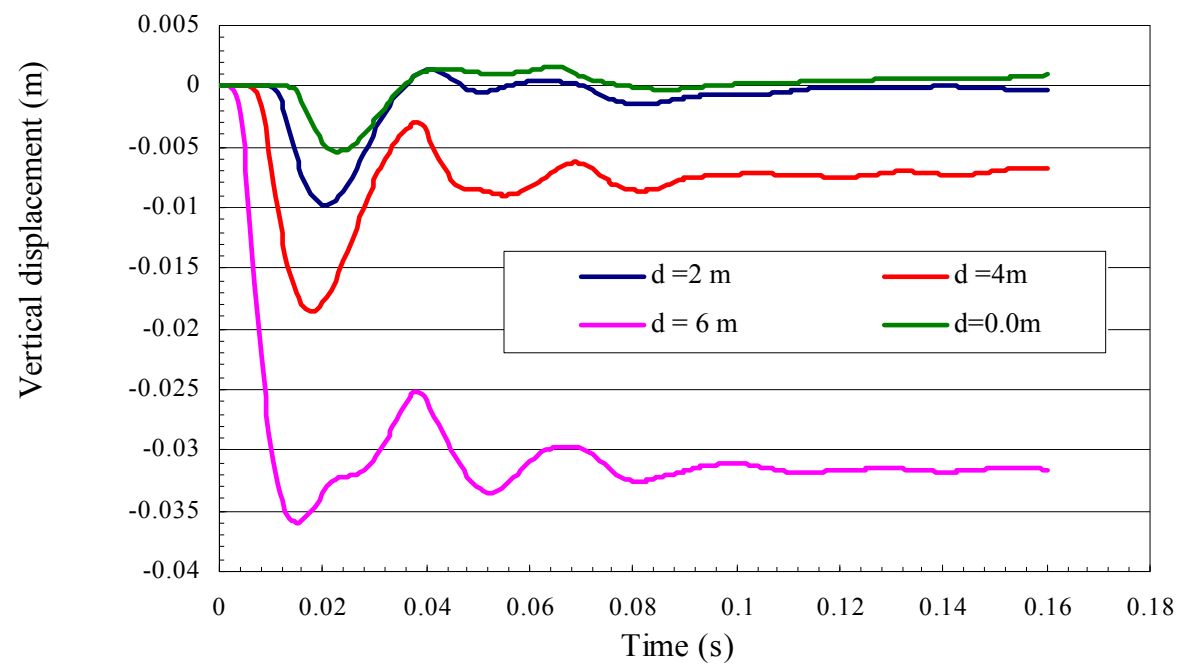

Figure 4 Vertical displacement time histories on the roof slab centre in different charge depths of burial cases

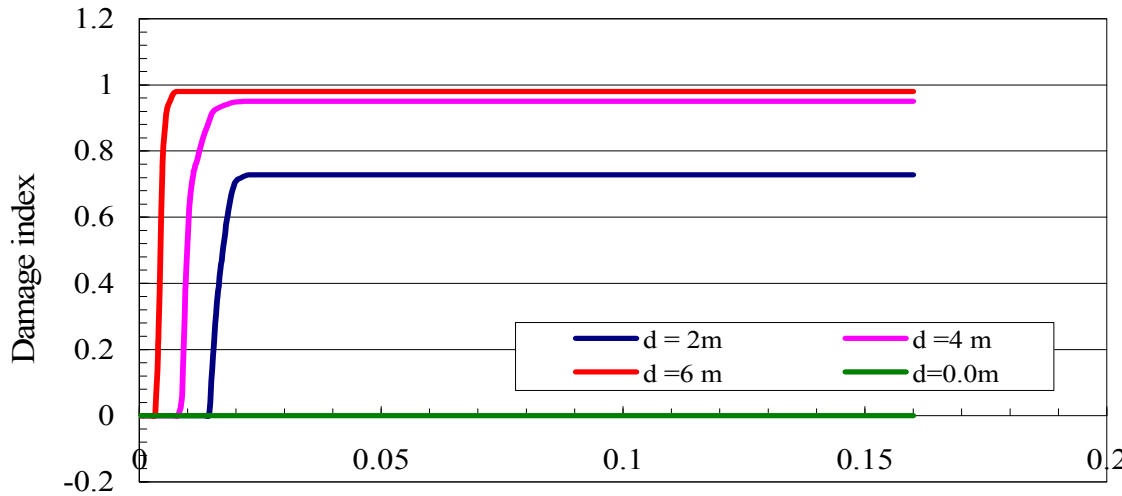

Time (s)

Figure 5 Damage index in different cases of the charge depth of burial

\subsection{Structure response with soil cover thickness of $\mathbf{2} \mathbf{m}$}

In order to investigate the effect of the soil cover between the structure roof and the explosion, a comparison is carried out between the cases of changing the structure depth of burial and the cases of changing the charge depth of burial.

Figure 8 presents the results of vertical displacement time histories on the roof slab centre in both cases of surface and buried explosion with the same $2.0 \mathrm{~m}$ soil cover thickness over the structure as shown in Figures 6 and 7. It can be seen that the behaviour of the roof centre point has the same trend but with significant difference in peak deflection and in permanent displacement.

It can be noticed that the maximum deflection in roof centre point in the case of surface explosion is $24.36 \mathrm{~mm}$ while in the case of buried explosion it is $35.9 \mathrm{~mm}$. It means that the 
response of the roof centre point increases by $32 \%$ in the case of the buried explosion. It can also be seen noticeably that significant permanent displacements of the roof structure slab occur in both cases. In the case of surface explosion the permanent displacement is $17.7 \mathrm{~mm}$ while in the buried explosion case the permanent displacement is found to be around 31.5 $\mathrm{mm}$, which means that the permanent vertical displacement increased in the buried explosion case by $44 \%$. These residual deflections indicate the occurrence of plastic deformation of the roof slab under the effect of these blast loads.

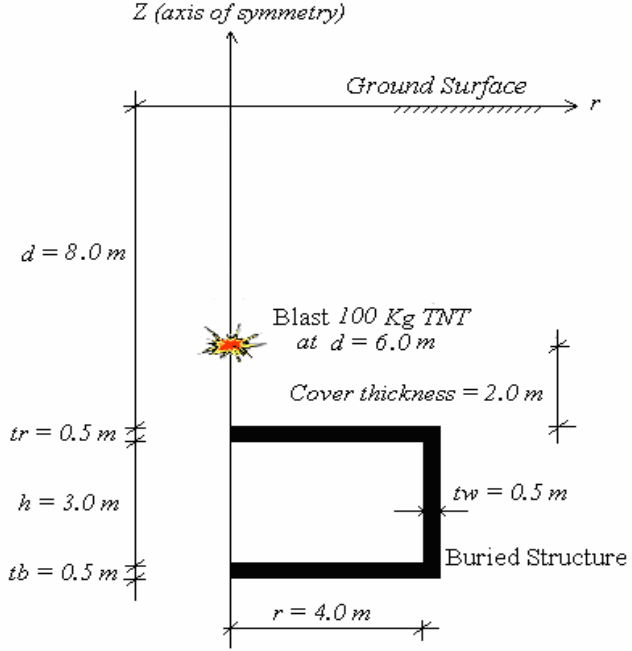

Figure 6 Schematic diagram of the buried charge case with soil cover $2.0 \mathrm{~m}$

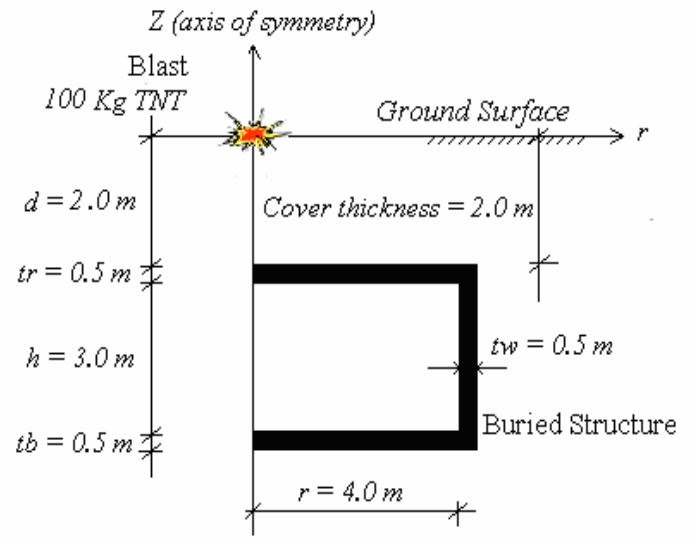

Figure 7 Schematic diagram of the surface charge case with soil cover $2.0 \mathrm{~m}$

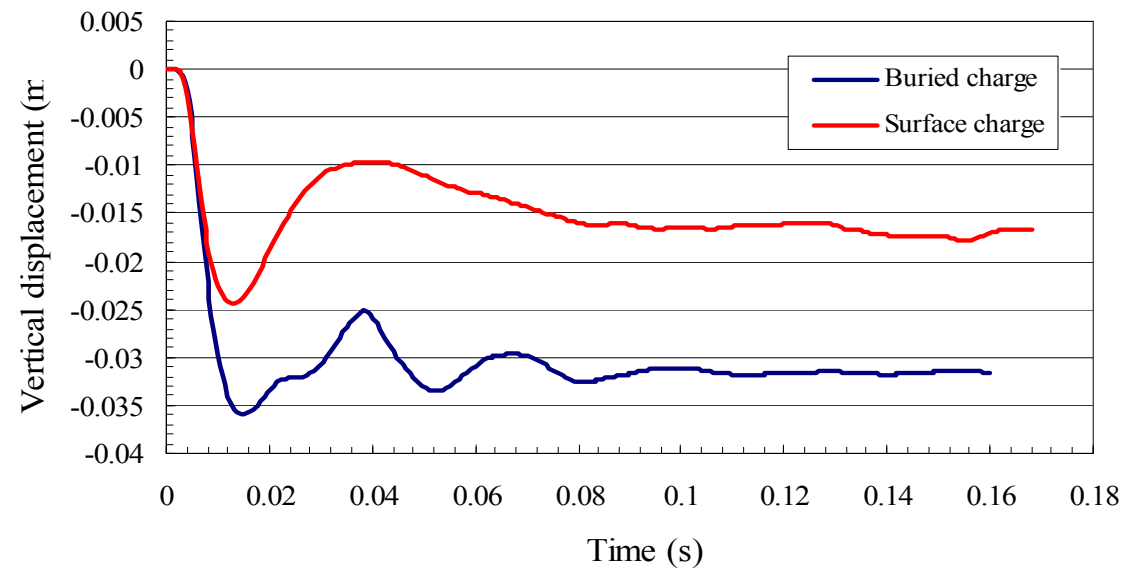

Figure 8 Vertical displacement of the structure roof centre for surface and buried explosions cases of $2.0 \mathrm{~m}$ soil cover

This is due to the confinement effect of the soil above the explosion in the case of the buried explosion which causes more blast energy to be directed downwards thus elevating the pressure experienced by the structure. In the case of the surface explosion some of the blast 
wave energy is released through the free surface to the surrounding less dense medium (air) causing less energy to be directed to the buried structure.

Figure 9 shows the concrete tensile damage in the structure roof centre for both cases buried and surface explosion with a soil cover layer of thickness $2.0 \mathrm{~m}$. It can be seen that in both cases the structure is severely damaged as it exerts damage index of 0.98 which means severely damaged [10]. It can be concluded that there is no significant difference between the two cases on the structure damage response when the explosion is near the structure in such a case of $2.0 \mathrm{~m}$ apart from the structure.

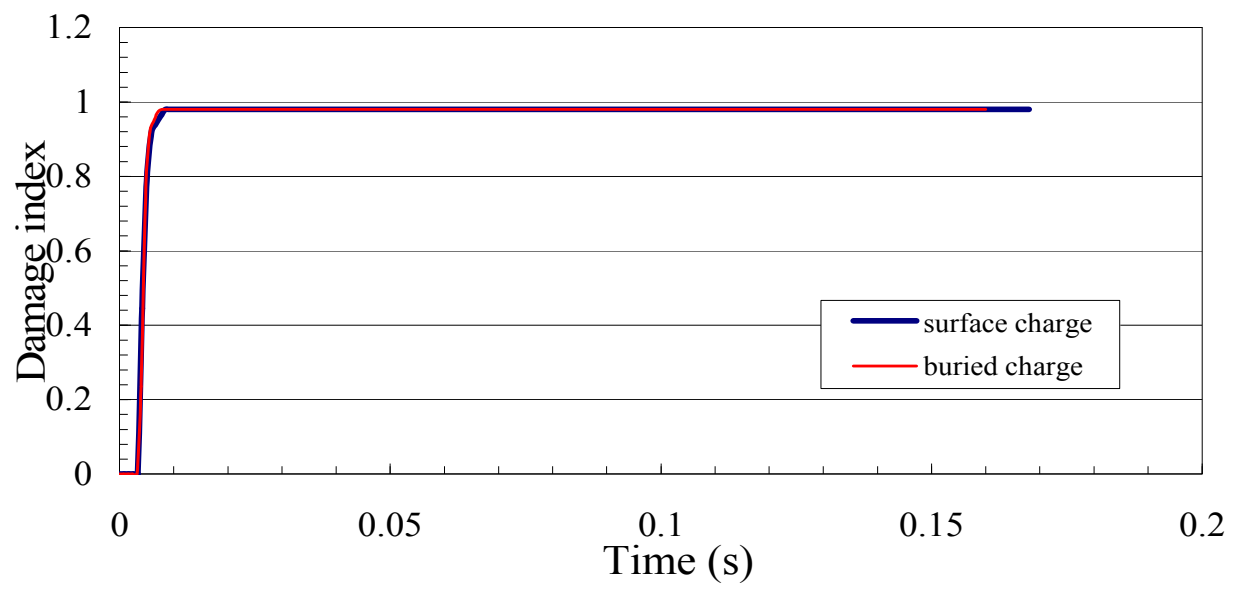

Figure 9 Damage of the structure roof centre for surface and buried explosions cases of $2.0 \mathrm{~m}$ soil cover

\subsection{Structure response with soil cover thickness of $\mathbf{4} \mathbf{~ m}$}

In this section the results obtained from the two situations illustrated in Figures 10 and 11 are compared. Figure 12 presents the results of vertical displacement time histories on the roof slab centre in both. It can again be seen that the behaviour of the roof centre point has the same trend but with significant difference in peak deflection and in permanent displacement. It can be noticed that the maximum deflection in roof centre point in the case of surface explosion is $12.5 \mathrm{~mm}$ while in the case of buried explosion it is $18.5 \mathrm{~mm}$ (a $32.4 \%$ increase). It can be seen that significant permanent displacements of the roof slab also occur in both cases. In the case of surface explosion the permanent displacement is $2.5 \mathrm{~mm}$ while in the buried explosion case the permanent displacement is found to be $7.31 \mathrm{~mm}$. It means that the permanent vertical displacement increased in buried explosion case by $66 \%$. These residual deflections indicate the occurrence of plastic deformation of the roof slab under the effect of blast loads.

It can be noticed that the increase of the response between the surface and buried explosion cases is more or less the same as for the previous case of the soil cover $2.0 \mathrm{~m}$ thick layer. This is due to the same influence of the soil confinement effect in the buried explosion case.

Figure 13 shows the concrete tensile damage in the structure roof centre for both cases. It can be seen that in both cases the structure is severely damaged as it experienced damage index of 
0.95 for the buried explosion case and damage index of 0.85 in case of surface explosion which means both structures are severely damaged [10]

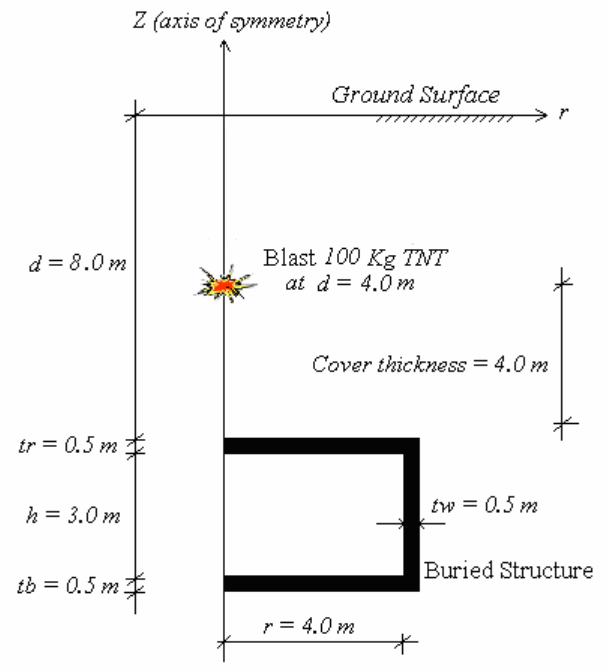

Figure 10 Schematic diagram of the buried charge case with soil cover $4.0 \mathrm{~m}$

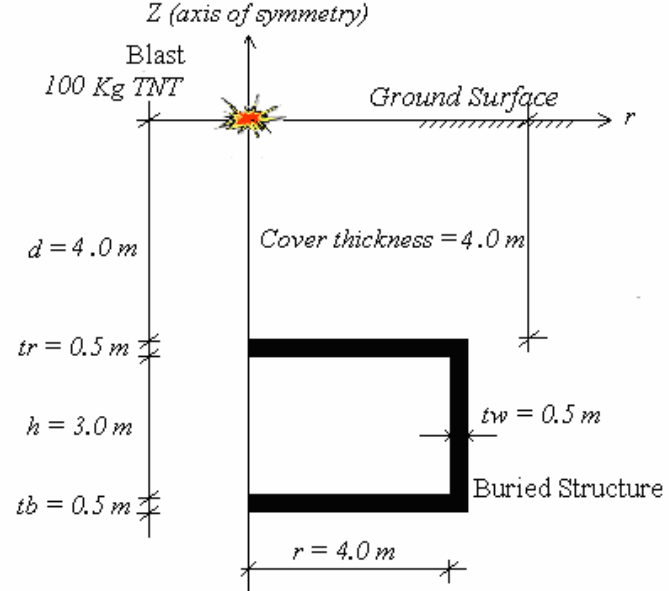

Figure 11 Schematic diagram of the surface charge case with soil cover $4.0 \mathrm{~m}$

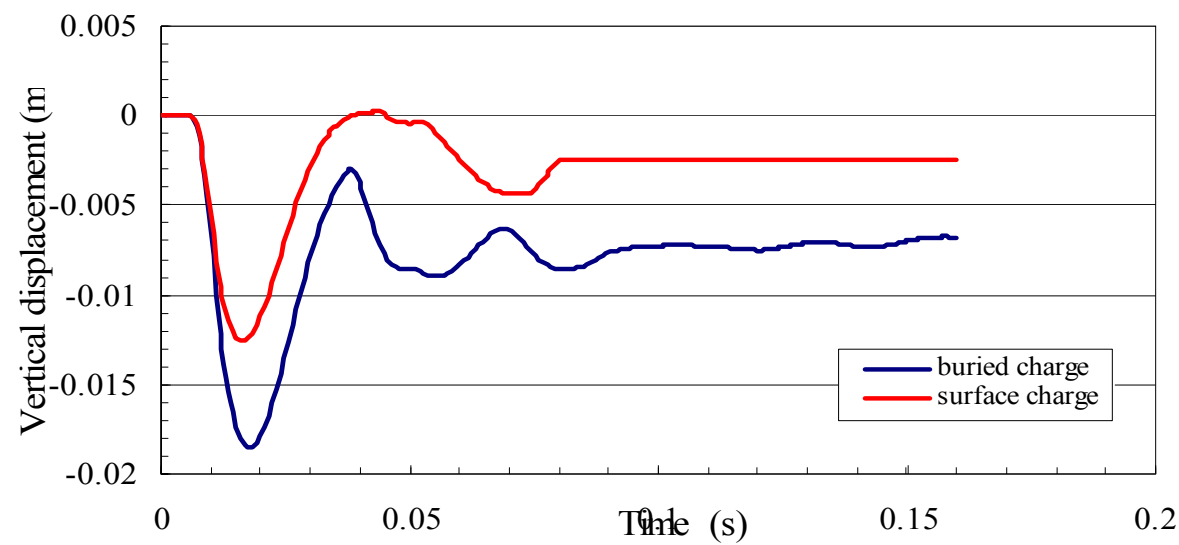

Figure 12 Vertical displacement of the structure roof centre for surface and buried explosions cases of $4.0 \mathrm{~m}$ soil cover

\subsection{Structure response with soil cover thickness of 6 m}

In this section the results of the case of buried explosion at depth $2.0 \mathrm{~m}$ on a buried structure at depth $8.0 \mathrm{~m}$ as shown in Figure 14 with the results from the case of surface explosion on a buried structure at depth $6.0 \mathrm{~m}$ as shown in Figure 15 are compared. Figure 16 presents the results of vertical displacement time histories on the roof slab centre in both cases. It can be seen that the behavior of the roof centre point has the same trend as before but with significant difference in peak deflection and in permanent displacement. The maximum deflection in roof centre point in the case of surface explosion is $8.23 \mathrm{~mm}$ while in the case of buried explosion it is $9.8 \mathrm{~mm}$. Thus the response of the roof centre point increases with $16 \%$ in the case of the buried explosion. 


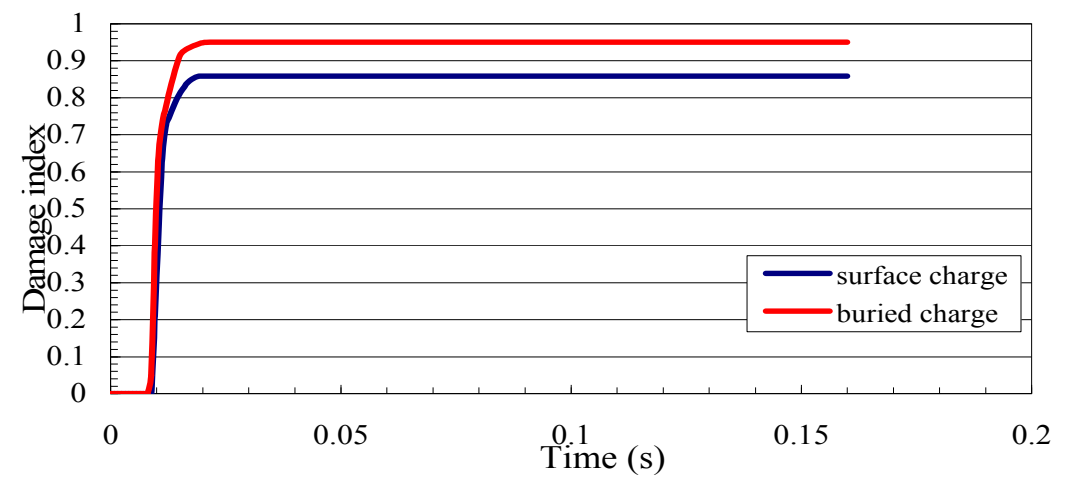

Figure 13 Damage of the structure roof centre for surface and buried explosions cases of $4.0 \mathrm{~m}$ soil cover

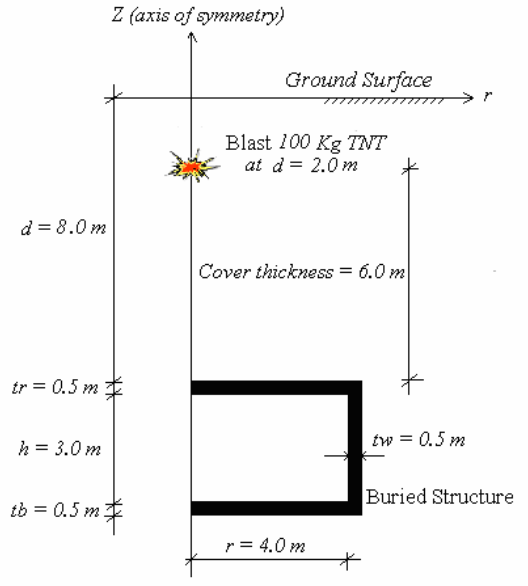

Figure 14 Schematic diagram of the buried charge case with soil cover $6.0 \mathrm{~m}$

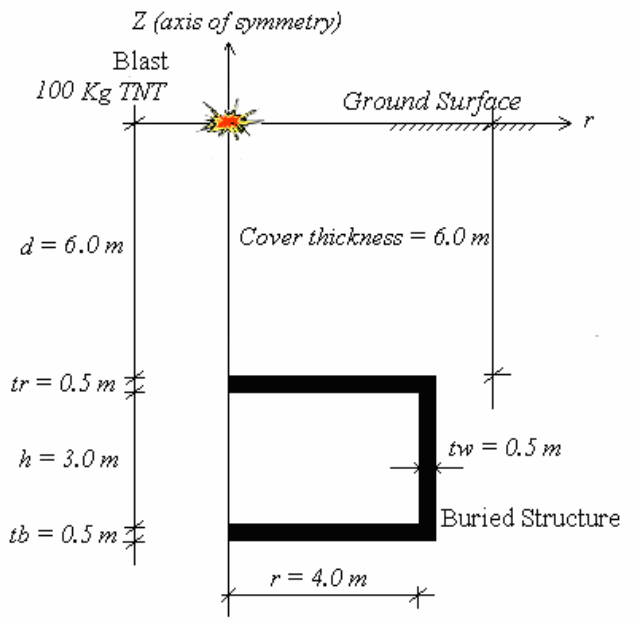

Figure 15 Schematic diagram of the surface charge case with soil cover $6.0 \mathrm{~m}$

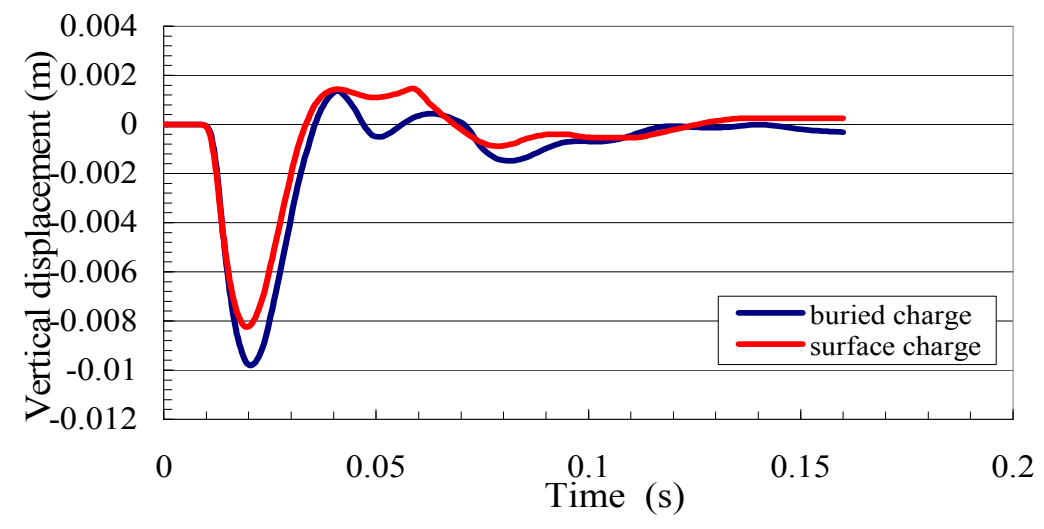

Figure 16 Vertical displacement of the structure roof centre for surface and buried explosions cases of $6.0 \mathrm{~m}$ soil cover 
It can be seen that no significant permanent displacements of the roof structure slab occur in either cases. In the both cases of surface and buried explosions the permanent displacement is in the range of 0.2 to $0.3 \mathrm{~mm}$, indicating that the soil cover $6.0 \mathrm{~m}$ thick acts as a good protection layer for the buried structure under the effect of the specified blast loads. It can be noticed that the increase of the response between the surface and buried explosion cases is less than for the previous case of the soil cover $4.0 \mathrm{~m}$ thick layer. This is due to that the structure is buried at a safer depth than previously considered.

Figure 17 shows the concrete tensile damage at the roof centre for both cases. It can be seen that in the buried explosion case the structure is highly damaged as it experienced damage index of 0.72 while in the surface explosion case the structure is experienced damage of 0.52 (a $31 \%$ reduction) which is in the medium damage zone [10].

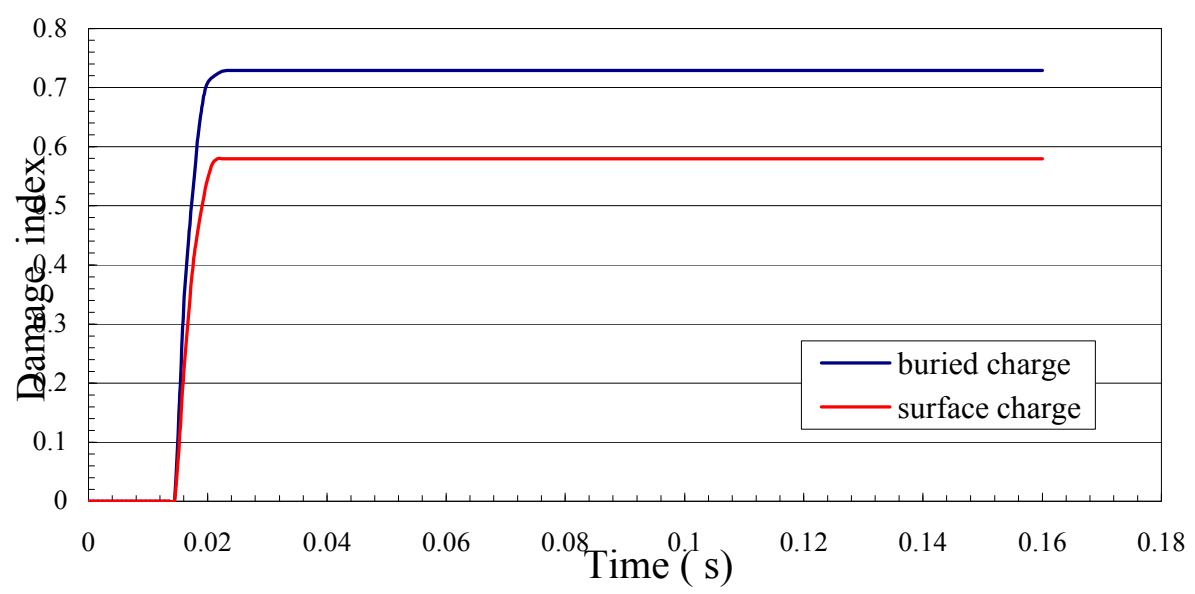

\section{Figure 17 Damage of the structure roof centre for surface and} buried explosions cases of $6.0 \mathrm{~m}$ soil cover

\section{6- Conclusion}

For depth of explosive charge burial variation investigation: Buried explosions result in a more significant difference on the structure response than the surface explosions with the same conditions. This is due to the confinement influence of the soil above the explosion in the case of the buried explosion which causes more blast energy to be directed downwards thus elevating the pressure experienced by the structure. Conversely, in the case of the surface explosion some of the blast wave energy is released through the free surface to the surrounding less dense medium (air) causing less energy to be directed to the buried structure. As presented, the investigation indicates that for the situation investigated the $6.0 \mathrm{~m}$ thick soil cover acts as a good protection layer for the buried structure under the effect of the specified blast loads. it can be concluded that at deeper depths may amplify the protective power and less response of buried shelter structures.

The new model, used in the investigation, provides researchers and designers with a computational tool for the design of buried concrete structures. Through FEA modelling, the damage failure mode and the damage failure locations can now be determined. In addition the extent of the strength and serviceability improvements that can be achieved by appropriate redesign of the system can be identified. The model can be used for parametric studies and 
verification of practical models, and in special design situations where great details of the responses are required. Besides the computational considerations, the proposed model makes use of a variety of material models; particularly noteworthy are the elasto-plastic DruckerPrager Cap model and the concrete damage plasticity model along with the JWL equation of state. It is concluded that these capture well the essential aspects of the materials involved. This final model has been found to accurately simulate the blast load pressure time histories affecting the buried structures and the dynamic soil structure interaction which has a significant effect on the structure response.

\section{References}

[1] Nagy, N., Dynamic Soil Structure Interaction of Buried Concrete Structures under the Effect of Blast Loads. 2007, University of Bradford, Bradford, UK.

[2] Nagy, N., M. Mohamed, and J.C. Boot. A Complete Nonlinear Finite Element Analysis for the Effects of Surface Explosions on Buried Structures. in the Eleventh International Conference on Civil, Structural and Environmental Engineering Computing. 2007. St. Julians, Malta: Civil-Comp Press, Stirlingshire, United Kingdom.

[3] ABAQUS Analysis Manual, ABAQUS Analysis User's Manual, Version 6.5. Published by Hibbitt, Karlsson and Sorensen Inc. USA, 2005.

[4] $\mathrm{Hu}, \mathrm{Y}$. and M.F. Randolph, A practical numerical approach for large deformation problems in soil. International Journal for Numerical and Analytical Methods in Geomechanics, 1998. 22(5): p. 327-350.

[5] ABAQUS Theory Manual, ABAQUS Theory Manual, Version 6.5. Published by Hibbitt, Karlsson and Sorensen Inc. USA., 2005.

[6] Ambrosini, R.D., et al., Size of craters produced by explosive charges on or above the ground surface. Shock Waves, 2002. 12: p. 69-78.

[7] Lee, E., M. Finger, and W. Collins, JWL equations of state coefficient for high explosives, in Lawrence Livermore Laboratory, Livermore, Calif, UCID-16189. 1973.

[8] Zhongqi, W., L. Yong, and H. Hong, Numerical Investigation of Effects of Water Saturation on Blast Wave Propagation in Soil Mass. Journal of Engineering Mechanics, 2004. 130(5): p. 551-561.

[9] Jankowiak, T. and L. Tomasz, Identification of parameters of concrete damage plasticity constitutive model. Foundations of civil and environmental engineering, 2005. 6: p. $53-69$.

[10] Kim, T.H., et al., Seismic damage assessment of reinforced concrete bridge columns. Engineering Structures, 2005. 27(4): p. 576. 